\title{
High Inductive Magnetic Stimuli and Their Effects on Mesenchymal Stromal Cells, Dendritic Cells, and Fibroblasts
}

\author{
J. PRŮCHA ${ }^{1,2}$, J. SKOPALIK ${ }^{3}$, I. JUSTAN ${ }^{4}$, T. PARÁK ${ }^{3}$, E. GABRIELOVÁ ${ }^{5}$, K. HÁNA ${ }^{1}$, \\ L. NAVRÁTIL ${ }^{2}$
}

${ }^{1}$ Department of Information and Communication Technologies in Medicine, Faculty of Biomedical Engineering, Czech Technical University, Prague, Czech Republic, ${ }^{2}$ Department of Health Care Disciplines and Population Protection, Faculty of Biomedical Engineering, Czech Technical University, Prague, Czech Republic, ${ }^{3}$ Department of Human Pharmacology and Toxicology, Faculty of Pharmacy, University of Veterinary and Pharmaceutical Sciences, Brno, Czech Republic, ${ }^{4}$ Department of Surgical Oncology, Faculty of Medicine, Masaryk University, Brno, Czech Republic, ${ }^{5}$ Department of Medical Chemistry and Biochemistry, Faculty of Medicine, Palacky University, Olomouc, Czech Republic

Received June 19, 2019

Accepted October 14, 2019

\section{Summary}

Effects of low-frequency electromagnetic fields (LF EMF) on the activation of different tissue recovery processes have already been fully understood. Preliminary recent data demonstrated that a special case of sinusoidal electromagnetic fields, known as amplitude-modulated currents (AMC) could have a potential to accelerate the cell metabolism or cell migration. An AMC generator was designed to generate sinusoidal induced electric currents with the amplitude modulation and the harmonic carrier frequency of $5,000 \mathrm{~Hz}$ was modulated by frequencies of 1 to $100 \mathrm{~Hz}$. The magnetic field peak was $6 \mathrm{mT}$, electric field intensity $2 \mathrm{~V} / \mathrm{m}$ and the current density of induced electrical currents was approximately $1 \mathrm{~A} / \mathrm{m}^{2}$. The coil of the generator was adapted to easy handling and safe integration into the shelf of the $\mathrm{CO}_{2}$ incubator. The shelf with the coil was prepared for the introduction of cells in standard plastic in vitro chambers. The tests focused on cells with migratory capacity after injury or during immunological processes and thus, mesenchymal stromal cells (MSC), dendritic cells (DC), and fibroblasts were chosen. The tests involved exposures of the cells to LF EMF (180 min/day) every day, for a period of three days, before examining them for cell death, morphology changes, and CD markers. The samples were tested by using MTT assay and the effects on the intracellular concentration of reactive oxygen species were quantified. The cell migration was finally measured with the help of the transwell migration assay. None of the cell types showed any decrease in the cell viability after the LF EMF application and the cells displayed
\end{abstract}

minimum changes in reactive oxygen species. Functional changes (acceleration of cell migration) after AMC exposure were statistically significant for the MSC samples only. The acceleration of MSCs is associated with the production of MMP by these cells. The EMF has a potential to be a safe, clinically applicable selective activator of MSC homing, MSC paracrine production, and subsequent regeneration processes.

\section{Key words}

Electromagnetic stimulation - Cell migration - Mesenchymal stromal cells • Fibroblasts • Dendritic cells

\section{Corresponding author}

J. Skopalik, Department of Human Pharmacology and Toxicology, Faculty of Pharmacy, University of Veterinary and Pharmaceutical Sciences, Palackého 1946/1, 61242 Brno, Czech Republic. E-mail: j.skopalik@gmail.com

\section{Introduction}

Mesenchymal stromal cells (MSCs) have a strong impact on many of the regenerative processes in the human body (Michalek et al. 2019). Their basic attributes are their migration across the extracellular matrix to inflammatory/ ischemic regions and effective action within these regions, including production of paracrine factors, mechanical connection to other cells, stabilisation of scar and 
necrotic/apoptotic tissue, and the release of bioactive compounds and exosomes (Altaner and Altanerova 2019, Skopalik et al. 2014, Altanerova et al. 2017). Dendritic cells (DCs) play a crucial role in the initiation of $\mathrm{T}$ and $\mathrm{B}$ cell responses in adult organisms, and their ability to migrate from different external tissues to the lymph nodes is important for the defence against pathogens and cancer cells (Strioga et al. 2013). Fibroblasts are the third type of cells with strong migration abilities, this feature being mostly manifested as their 'collective migration', which is of importance in the wound healing process (Sakar et al. 2016).

A broad community of medical engineers and authors of ICNIRP Guidelines (Guideline 1998) are using the nomenclature, which presents definition of three basic coupling mechanisms through which time-varying electric and magnetic fields interact directly with living matter:

(i) coupling to low-frequency electric fields (under $100 \mathrm{kHz}$ ), (ii) coupling to low-frequency magnetic fields, (iii) absorption of energy from electromagnetic fields (above $100 \mathrm{kHz}$ ). For the variant (i), electric fields external to the body induce currents in the body (dimension $1 \mathrm{~A} / \mathrm{m}^{2}$, deatils in Guideline 1998) The high inductive magnetic stimulation of tissues and the mechanism of their interaction with MSCs belong to relatively poorly described biophysical phenomena. This phenomenon is mostly associated with induced ion channel opening and affects the mitochondrial metabolism and mitotic activity of nuclear components (Shupak et al. 2003, Pitr and Prucha 2001, Prucha et al. 2004). The ability of alive organisms to react on external time-variable magnetic fields is supported by results of the research dealing with the animal magnetoreception (Capek et al. 2017). Our pre-clinical results showed that this stimulation could also help the final cell motility and production of MMP-2, which is important for the cell migration through the collagen extracellular matrix and extracellular matrix rebuilding in tissues.

At the same time, the high-induction magnetic stimulation means the application of time-variable low frequency elektromagnetic fields, producing induced electric currents in living tissues at a current density of about $1 \mathrm{~A} / \mathrm{m}^{2}$ or above. Sufficient research data have not yet been presented for these stimulating electric signals. On the other hand, results of certain studies (Prucha et al. 2018) indicate significant effects of these signals on certain cell types (sensory neurons), in which the intracellular calcium concentration and their spontaneous activity are affected. That paper demonstrated that F11 cells used, derived from dorsal root ganglia neurons as an in vitro model of peripheral sensory neurons, and three different protocols of high-induction magnetic stimulation determine the effects on the chemical responsiveness and spontaneous activity. short-term ( $<180$ s) exposure of F11 cells to LF-EMF was shown to reduce calcium transients in response to bradykinin, a potent pain-producing inflammatory agent formed at sites of injury. Moreover, this result characterizes an immediate and reversible potentiating effect of LF-EMF on the neuronal spontaneous activity. This result provides a new evidence that the electromagnetic field may directly modulate the activity of sensory neurons.

\section{Methods}

\section{Cell samples}

Three types of cells were used to test EMF irradiation effects: commercial fibroblasts 3T3; human MSCs; and human DCs. The 3T3 cell lines were obtained from Sigma-Aldrich (93061524) in a cryo-conserved form, while the MSCs were isolated from healthy donors undergoing small subdermal intervention at anesthetic ambulance and the DCs were isolated from healthy donors' peripheral blood. All tissues used were obtained from healthy patients after receiving their written informed consent in accordance with the Czech Republic law 372/2011 and the Declaration of Helsinki.

The MSCs were isolated from the adipose tissue of three healthy donors who underwent the cosmetic liposuction. The cells were isolated by incubating lipoaspirates with collagenase and then expanded in the complete Dulbecco's modified Eagle's medium (plus $5 \%$ platelet lysate) for three weeks. Further details regarding the isolation and incubation were described by Siciliano et al. (2016). Typical MSC phenotypes (CD90, CD73, and CD 105 surface molecules) and the adipo/ osteo/chondro-genic potential were evaluated for each culture from each donor before the EMF experiments (details in Cmiel et al. 2017).

The DCs were isolated from the sterile 'buffy coats' of the human peripheral blood. The peripheral blood mononuclear cells (PBMC) were separated by the density gradient centrifugation layered over Histopaque (SigmaAldrich) and the monocytes were isolated as the adherent fraction of PBMC after two $\mathrm{h}$ of incubation at $37{ }^{\circ} \mathrm{C}$ in the CellGro DC medium (CellGenix, Freiburg, Germany) with $50 \mu \mathrm{g} / \mathrm{ml}$ DNase I (Roche, Mannheim, Germany). After washing, the adherent monocytes were cultured for six days in the CellGro DC medium for the final maturation of the DCs (details of procedure published in Vopenkova et al. 2012). 


\section{Construction of amplitude-modulated current generator}

The cells studied were subjected to the action of the time-variable low-frequency magnetic field. This field produces induced electric currents in cells and their surroundings. The time course of these currents is harmonic - sinusoidal with a frequency of $5 \mathrm{kHz}$. The modulating sine wave signal is superimposed on this so called carrier frequency - carrier signal. This modulating signal varies its frequency from 1 to $100 \mathrm{~Hz}$ and back from $100 \mathrm{~Hz}$ to $1 \mathrm{~Hz}$ with a period of $12 \mathrm{~s}$ and triangular course. See Fig. 1 for time relationships.

A

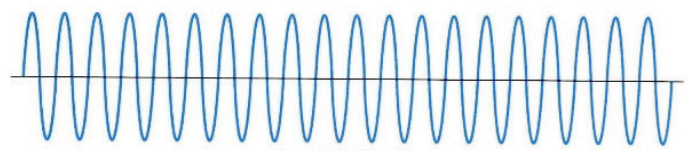
Carrier Signal

B

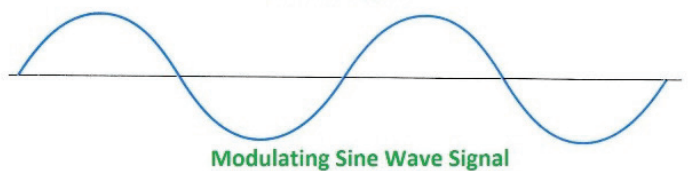

c

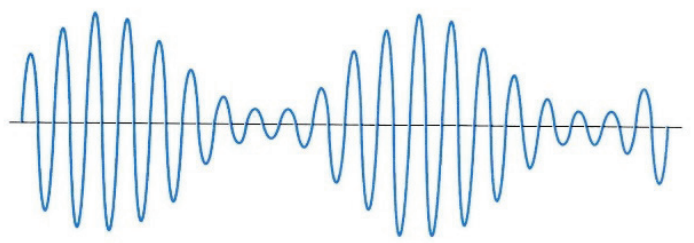

Amplitude Modulated Signal

Fig. 1. Illustrations of carrier signal $5 \mathrm{kHz}(\mathbf{A})$, modulating sine wave signal 1 to $100 \mathrm{~Hz}$ (B), and final sinusoidal amplitude modulation (C). Modified from (Shupak et al. 2003), see also: https://www.quora.com/How-does-amplitude-modulation-work.

The induced electrical current exerting the harmonic sinusoidal course at the frequency of $5 \mathrm{kHz}$, but also low frequency beats with frequencies slowly and repeatedly varying from $1 \mathrm{~Hz}$ up to $100 \mathrm{~Hz}$ and back, are applied in this way onto the cell culture. The induced electrical current with these parameters, providing in its amplitudes a current density of $1 \mathrm{~A} / \mathrm{m}^{2}$ in the cell culture, is obtained in a contactless manner as a result of corresponding time variations of the magnetic field. This time-variable, non-stationary magnetic field is produced with the help of two tightly neighbouring ring-shaped coils having $8 \mathrm{~mm}$ in diameter and situated in one plain, above which the cell cultures to be irradiated shall be placed. At the same time, the interference principle is employed for the amplitude modulation of the harmonic signal at $5 \mathrm{kHz}$. The electrical current with the harmonic time course and frequency of $5000 \mathrm{~Hz}$ is conducted into one coil. The electrical current also exerting the harmonic time course, but frequencies of $5000 \mathrm{~Hz}+(1 \mathrm{~Hz}$ to $100 \mathrm{~Hz}$ ), i.e. 5001 to $5100 \mathrm{~Hz}$, is then continuously conducted into the second coil. In this way, a region originates above the coils, in which the time course of the inducing time-variable magnetic field as well as the time course of the electrical currents induced, characterized by the carrier frequency of $5000 \mathrm{~Hz}$ and amplitude sine modulation with continuously, slowly varying frequencies of 1 to $100 \mathrm{~Hz}$ (see Fig. 1) are implemented. We thus used the interference for the modulation, which, could make us possible to obtain a doubled signal amplitude. Based on this principle, certain clinical studies are carried out, objectivizing effects of the contactless application of electrical currents in treating pain and supporting healing (Prucha et al. 2004, Pitr and Prucha 2001). The physical intervention described was applied twice a day for time periods of $90 \mathrm{~min}$.

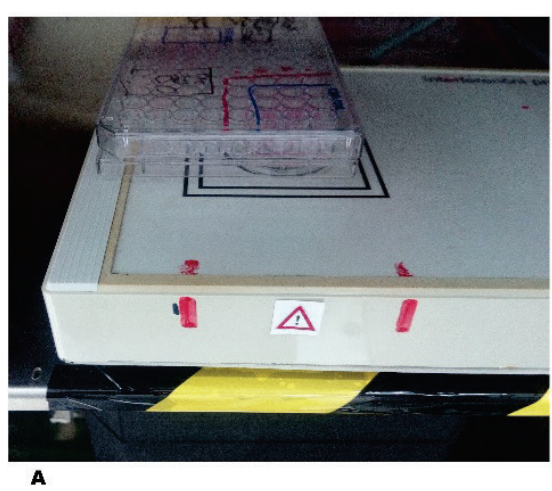

Fig. 2. EMF applicator and cell sample irradiation. (A) 96-well plate on EMF applicator (white plastic box isolated against humidity) assembled into the $\mathrm{CO}_{2}$ incubator. Cells are always set to geometrical axis of coil (1 cm above the square with black lines), sample space dimension is " $4 \times 4$ chambers of 96 well-plate" (equivalent to $2 \times 2$ chambers with 24-well plates). (B) Inserts with cells applied to 24-well plate at time of starting test for cell migration. (C) 24-well plate with four inserts in sample area of applicator. EMF intensity on well bottom was $6 \mathrm{mT}$ (measured by Teslameter type Lake Shore 460, Lake Shore Cyryotronics, USA), electrical field intensity was of $2 \mathrm{~V} / \mathrm{m}$ and density of electrical currents induced was of about $1 \mathrm{~A} / \mathrm{m}^{2}$ (measured by ESM-100 H/E fieldmeter, Germany). 


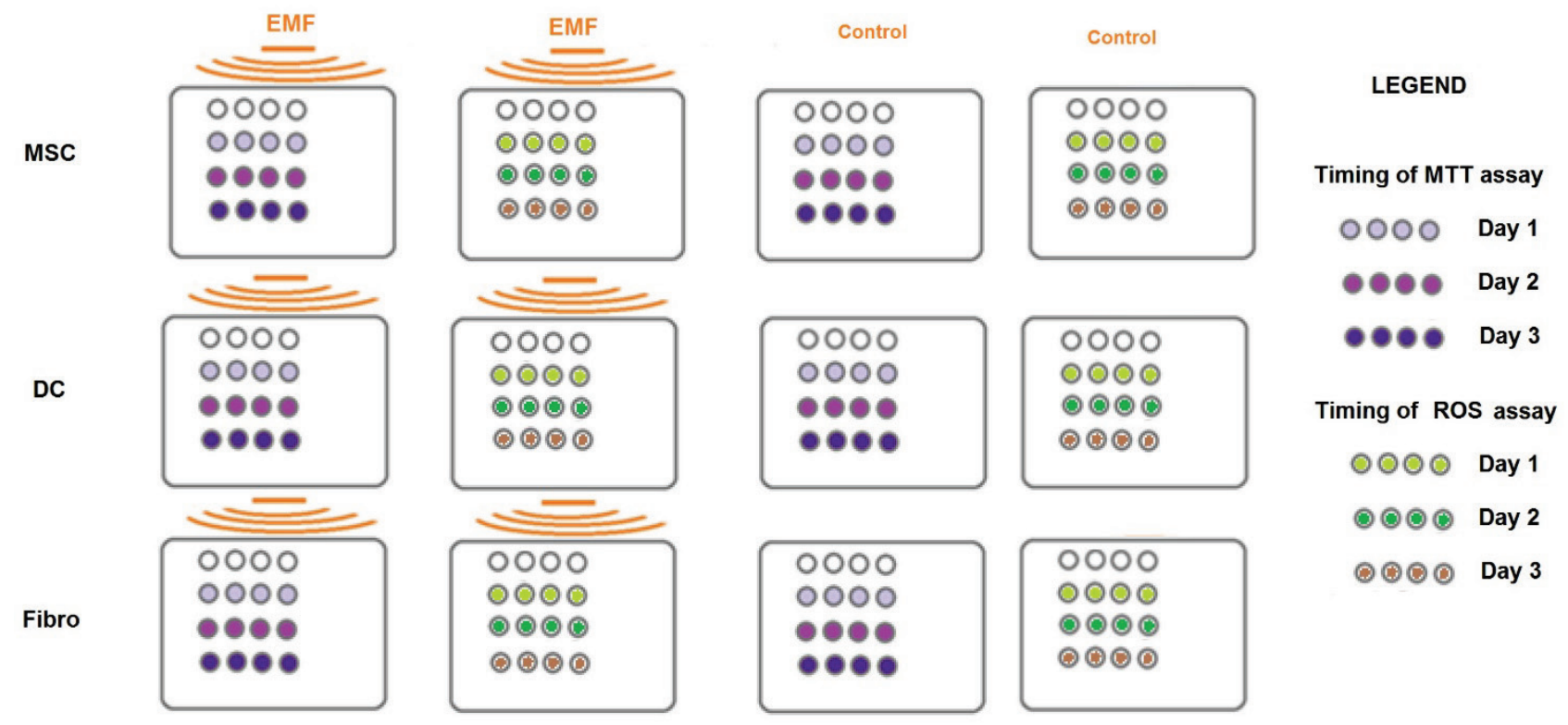

Fig. 3. Scheme of the MTT assay and ROS assay applied on the EMF-exposed and control cells. Each cell sample (MSC, DC, fibroblast) was divided and seeded to four 96-well plates. First and second plates were exposed to EMF and the third and fourth plates were controls. First and third plates were used for MTT assay and second and fourth plates were used for ROS assay. Cells were daily exposed to EMF for $2 \mathrm{x}$ $90 \mathrm{~min}$. MTT and ROS tests were performed on each sample in random steps after one day, two days, and three days of exposure to EMF.

Cell culture, EMF application, and detection of cell reaction by MTT and ROS assay

The MSCs, DCs, and fibroblasts were seeded onto 96-well plates (2,000 cells in each well). The plates were placed near the EMF applicator (Fig. 2) and the EMF was applied for $2 \times 90 \mathrm{~min}$ a day for one to three days. The times for the EMF exposure and the timings of the different measurements (MTT, ROS assay) are specified in Fig. 3.

\section{ROS assay}

Reactive oxygen species (ROS) are associated with cell stress and pathological cell changes. The MSCs, DCs, and fibroblasts were seeded into 4x16 wells (2,000 cells/well in 96 wells) and exposed to EMF for one, two, or three days $(180,360$, or $720 \mathrm{~min}$ in total) (see Fig. 3 for details). For testing a potential oxidative stress caused by the EMF, $2 \mu \mathrm{l}$ of the fluorescent ROS probe (general oxidative stress indicator; CM-H2DCFDA, Invitrogen) was then added into each well (final concentration $10 \mu \mathrm{mol} \cdot \mathrm{l}^{-1}$ ). The plate was incubated for $45 \mathrm{~min}$ and the fluorescent signal was measured using the Infinite PRO M200 microplate reader (Tecan, Austria) with laser excitation $505 \mathrm{~nm}$ and detected emission $529 \mathrm{~nm}$. The intensity of the fluorescence of cells was measured under $25{ }^{\circ} \mathrm{C}$, irradiated samples were compared with a control sample (no exposure to the EMF). All tests for each MSC, DC, and fibroblast sample were repeated three times (three parallel cell samples at the same initial cell density) and a statistical summary was computed.

\section{MTT assay}

The metabolic activity was measured using commercial tetrazolium dye colorimetric assay (standart output called as MTT-index), which shows the cellular growth and viability (Sigma-Aldrich, Inc., MO, USA). The cells were incubated in MTT for four h (Sylvester et al. 2011) and the wells were then rinsed with dimethyl sulfoxide in accordance with the manufacturer's instructions. The final measurement of the absorption (at $530 \mathrm{~nm}$ ) of each cultivation well was performed using the Elisa-reader Paradigm instrument (Arnold O. Beckman, Inc., CA, USA). As a result, the comparison of the metabolic activity of irradiated cells and the control samples was obtained, details in Figs. 4-B//5-B.

Additional basic quantification of cell growth and viability (calcein method)

The absolute number and ratio of viable/nonviable cells in all cells samples after three days of the EMF exposure were measured using calcein + ethidium homodimer-1 (L3224, ThermoFischer) staining and enumeration of live and death cells in at least five fields of view (microscope Olympus IX70, objective 20x, exc. 490/em. $510 \mathrm{~nm}+$ exc. 530/em. $610 \mathrm{~nm}$ ). 
Evaluation of electromagnetic stimulus for migration activity - Transwell migration assay for MSC tests

The migration capacity of MSCs was assessed using the Corning Costar 24-well Transwell chamber system assay kit ( $8-\mu \mathrm{m}$ size). The aim of the assay is to quantify the number of cells that have passed through a polycarbonate membrane after $12 \mathrm{~h}$. The membranes of the chamber were coated with gelatine $(1 \% \mathrm{w} / \mathrm{v})$ for $1 \mathrm{~h}$ at $37^{\circ} \mathrm{C}$. The uniformity of the gelatine layer was checked using Leica SP8 microscopy in reflexive mode before the cells were seeded. Migration experiments were done with $1 \times 10^{4}$ MSCs. MSCs were applied to the transwell chamber after 3 days of EMF prestimulation (control cells with no prestimulation). The cells were placed into the transwell chamber in the form of $500 \mu \mathrm{l}$ suspension (in DMEM, serum free), and after that, $10 \%$ FBS was added to the lower chamber. Three transwell chambers were placed in the $\mathrm{CO}_{2}$ incubator in the sample area of the EMF applicator (Fig. 2, exposed to EMF $2 \mathrm{x}$ $90 \mathrm{~min} / 24 \mathrm{~h}$ ) and another three transwell chambers filled with unstimulated cells were incubated without exposure to EMF. After $12 \mathrm{~h}$, the cells in the lower inserts were stained with calcein and observed under a fluorescence microscope (exc. $490 \mathrm{~nm} / \mathrm{em}$. $510 \mathrm{~nm}$ ). Five randomly selected fields were quantified for each insert and the average number of transmigrated cells and the ratio of EMF sample/control sample were computed. Three independent MSC samples were used for the final statistical summary.

\section{Transwell migration assay for $D C$ tests}

The migration ability of DCs was assessed using the Corning Costar 24-well Transwell chamber system assay kit $(5-\mu \mathrm{m}$ size). Transwell inserts $(6.5 \mathrm{~mm}$ diameter) were coated with $20 \mu \mathrm{g} / \mathrm{ml}$ murine collagen IV (BD Biosciences) and left in PBS overnight. Migration experiments were performed by applying $1 \times 10^{5}$ cells to the RPMI medium in the upper well (see MSC tests in Fig. 4). Migration of DC was tested toward (i) zero chemokines gradient, (ii) the chemokines CCL3 (10 nM in lower compartments in a total volume of $400 \mu \mathrm{l}$ medium). Both variants were tested, i.e. with or without EMF exposure. Migrated cells were stained with calcein and observed under a fluorescence microscope after $3 \mathrm{~h}$ incubation in the $\mathrm{CO}_{2}$ incubator.

\section{Scratch migration assay for fibroblast tests}

The cell motility of the fibroblasts was studied using the scratch assay (model of wound healing). For this assay, three-day-old cultures were prepared in confluent cell layers ( $3.5 \mathrm{~cm}$ dish, TPP Techno Plastic Products AG). The first dish contained cell cultures that had been EMFstimulated for three days and the second dish contained cells that had not been EMF- stimulated. Scratch $(0.8 \mathrm{~mm}$ wide) was drawn through a confluent cell layer on both culture dishes, the culture medium was changed, and the dishes were put back into the $\mathrm{CO}_{2}$ incubator. The first dish was then exposed to EMF, again $(180 \mathrm{~min} / 12 \mathrm{~h}$ ). Afterwards, the cell migration was assessed using the phase contrast mode of a microscope (Olympus IX70). The growth and migration of the fibroblasts reduced the width of the central cell-free zone. The cell-free zones in the dishes were quantified after $12 \mathrm{~h}$ from five different fields of view (objective 10). The average width of the EMF-stimulated sample was compared with the average width of the control sample. The experiments were repeated in triplicates.

\section{Additional quantification of MMP-2 on MSC after EMF stimulation}

Transwell chambers were prepared using the same method as described in 'Transwell migration assay MSC tests'. On the third day, the cells from five chambers that had been exposed to EMF stimulation and five chambers that had not been exposed to EMF stimulation were lysed in a RIPA Lysis Buffer containing $1 \%$ PMSF at $4{ }^{\circ} \mathrm{C}$. The lysate was then cleared by centrifugation and the supernatant was collected and
A

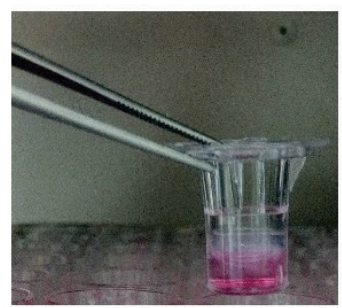

B

Start of the cells migration

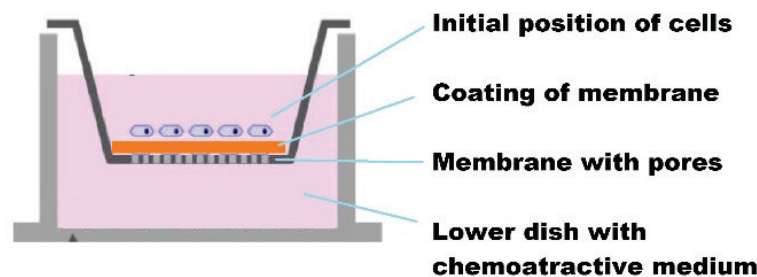
End of the experiment

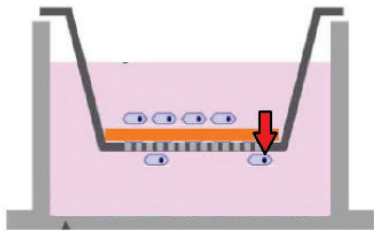

Fig. 4. Transwell chamber. (A) Illustrative photo. (B) Scheme of cell distribution at starting time. (C) Cells after 24-hrs migration. 
A

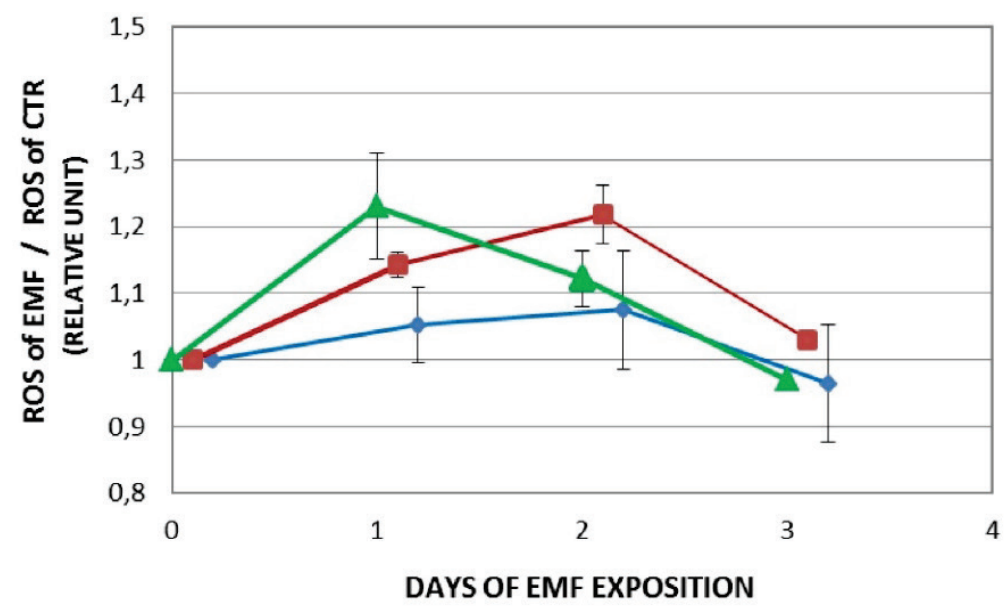

B

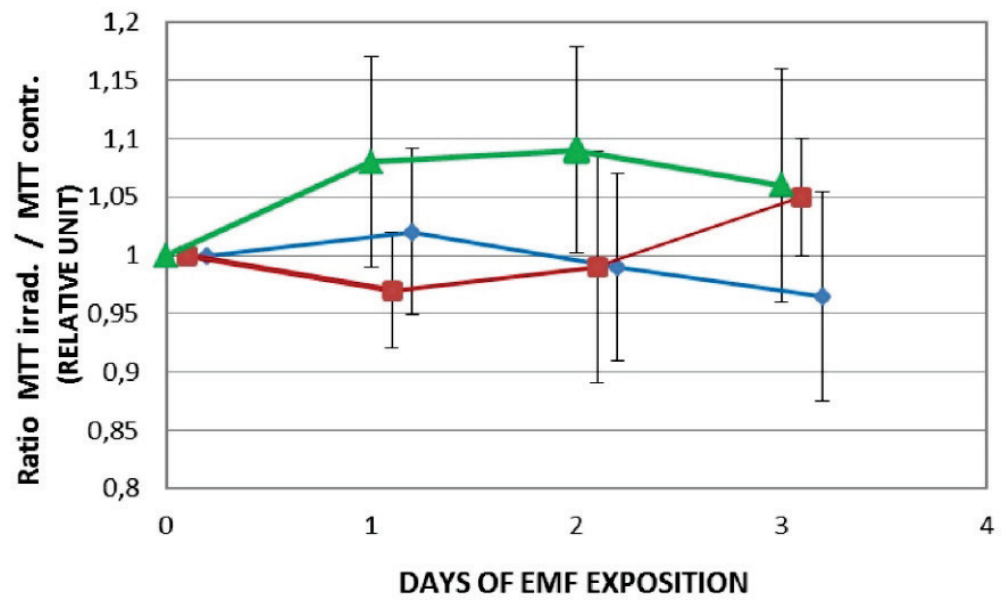

Fig. 5. (A) ROS characteristic after different lengths of EMF stimulation. Each point for each cell culture was constructed as a value of ROS fluorescence detection from EMF-stimulated cells/value of ROS fluorescence detection from control cells. Green: average from three samples of MSCs; red: average from three samples of DCs; blue: average from three samples of fibroblasts. (B) MTT assay for the MSCs, DCs and fibroblast (the same color as used in ROS graph), output of the machine was in from of MTT index for each sample, these value was used for computing the final ratio: MTT of irradiated sample / MTT of control sample. quantified. Equal of protein were separated by SDS-PAGE on a $12 \%$ running gel and $5 \%$ stacking gel and the protein blots were then transferred to a PVDF membrane.

The membrane was then incubated with a primary antibody (rabbit anti-MMP-2 [H-76], anti-actin [I-19] antibody; BSA [5\%, w/v] in TBS/T) overnight at $4{ }^{\circ} \mathrm{C}$ and then with a secondary horseradish peroxidase conjugated antibody (goat anti-rabbit antibody and rabbit anti-goat antibody; BSA [5\%,w/v] in TBS/T) for $1 \mathrm{hr}$ at room temperature; purchased from Santa Cruz Biotechnology (USA). The protein/actin expression was detected by chemoluminescence using Western Blotting Luminol Reagent and autoradiography with Carestream Biomax Light film. The quantification of the protein was performed using a dosimetric analysis conducted with the image processing software ImageJ.

\section{Results}

Basic tests of EMF biocompatibility

The viability of the MSCs, DCs, and fibroblasts after the three-day EMF application was $98.3 \% \pm 1.1$,
$98.5 \% \pm 1.4$, and $97.0 \% \pm 2.1$, respectively (versus $98.1 \% \pm 1.3,98.1 \% \pm 1.6$, and $96.85 \% \pm 2.1$, respectively in the control cells). The results showed that the viability was not affected by the EMF. The MSCs, DCs, and fibroblasts did not show any significant change in the growth of cell mass during the first three days in the in vitro chambers under the EMF exposure.

The final graphical overview of the ROS value detected in the MSCs, DCs, and fibroblasts can be seen in Fig. 5A. A small increase in ROS in the first or second day was visible in all cell cultures, but the value from the third day shows a decrease in the initial value, indicating the adaptation of the cells to the EMF stimulus. Results of MTT assay for the MSCs, DCs and fibroblast are presented in Fig. 5B.

Visual control of cells by microscope during 3 days of the EMF application excluded any induction of cell malformation or visible cell apoptosis. We found that the morphology of the MSCs, DCs, and fibroblasts remained unaltered after the electromagnetic stimulation; no change was detected during first three days or in the additional tests (eight days of EMF exposure). All 
parameters (average cell size and cell surface) were the same as in the control cells (Fig. 6).

\section{Potential of cell migration}

The MSC migration through transwell inserts was computed at the time point " $+12 \mathrm{~h}$ " after the cell seeding onto the coated membrane. The cells exposed to the EMF showed 1.3 times the number of transmigrated cells compared to controls (an illustrative field of view is shown in Fig. 7). An overview of the results from the three donors is presented in Fig. 7C.
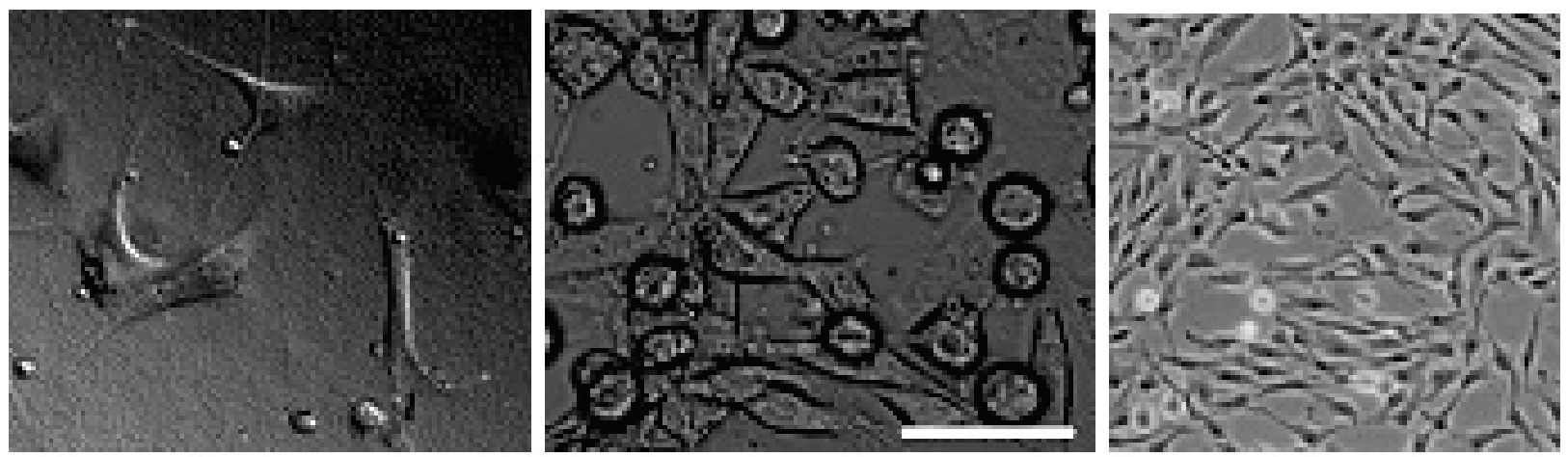

Fig. 6. Overview of cell morphology on third day of EMF application (MSCs, fibroblasts, DCs from left to right).

A

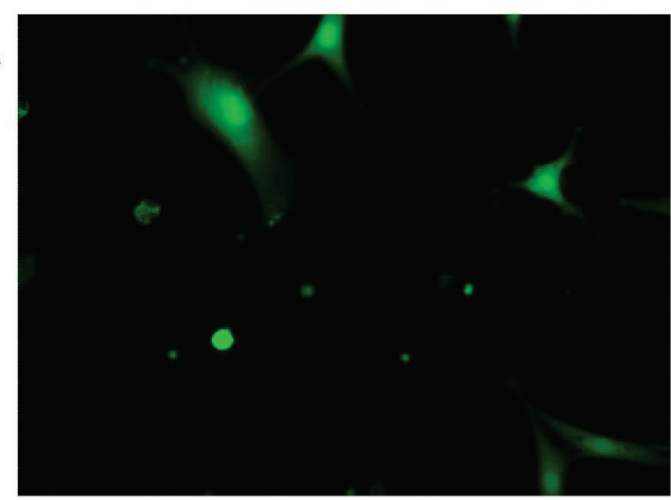

$\mathbf{B}$

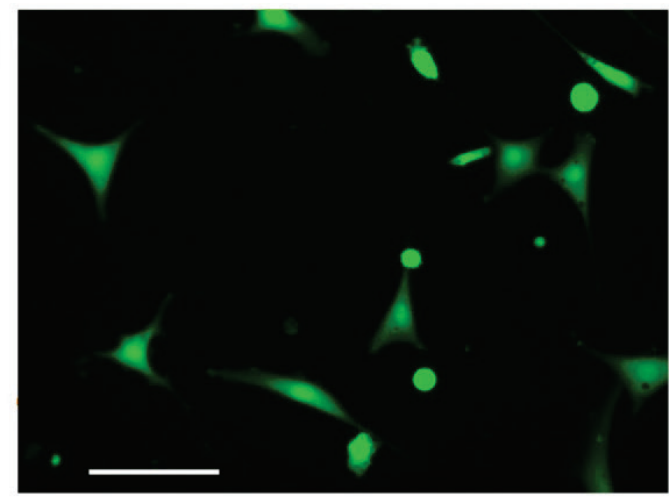

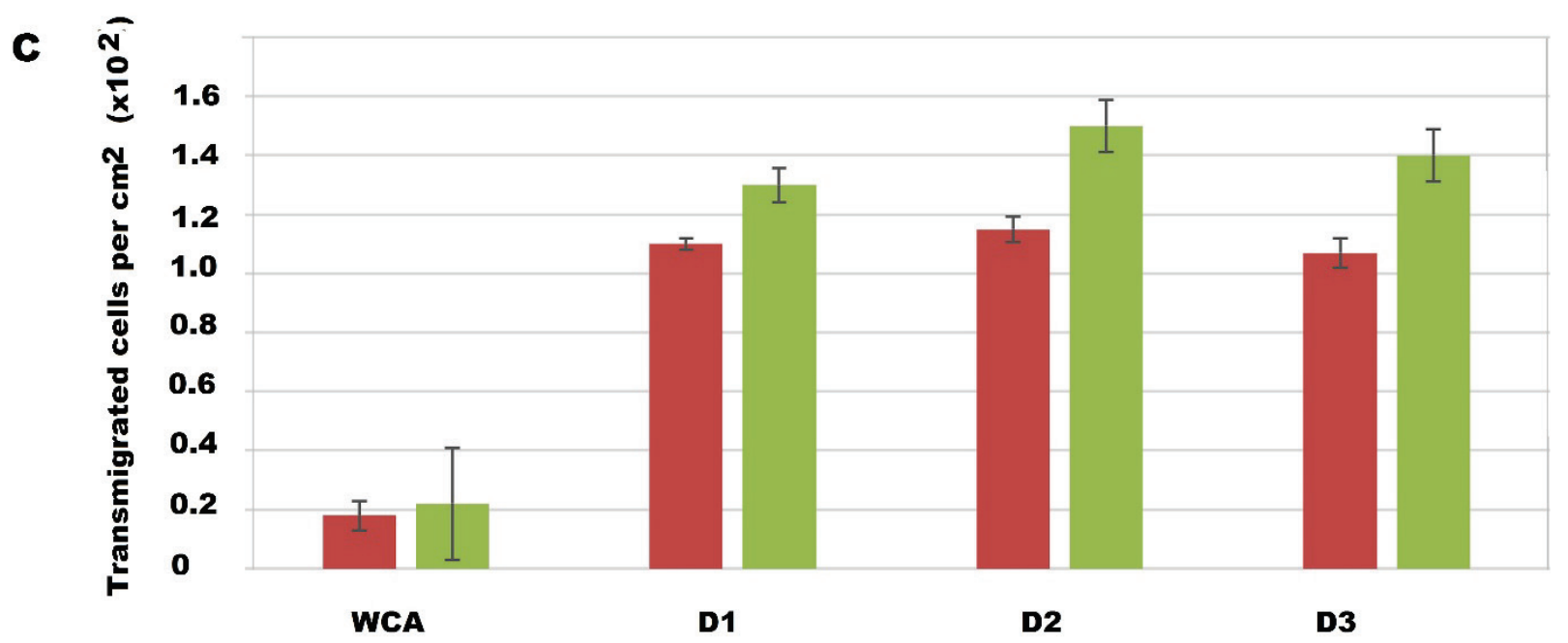

Fig. 7. Results of MSC transmigration. (A) Illustration of transmigrated calcein positive cells (green fluorescent) from control chamber and (B) from EMF stimulated chamber. Bar $100 \mu \mathrm{m}$, Olympus IX70, objective 20x, exc. 490/em. $510 \mathrm{~nm}$. (C) Statistical overview of transmigration from three different MSC samples (three donors: D1, D2, D3; red bars: cells without EMF stimulation; green bars: cells with EMF stimulation; all donor samples showed significant increases; values are expressed as means \pm SD from two membranes and 10 randomly selected fields of view; results for each donor were considered at $p<0.05$ for difference between EMF and control). $W C A=$ values representing control experiments without setting of chemotactic gradient on insert membranes (average from all three donor samples). 


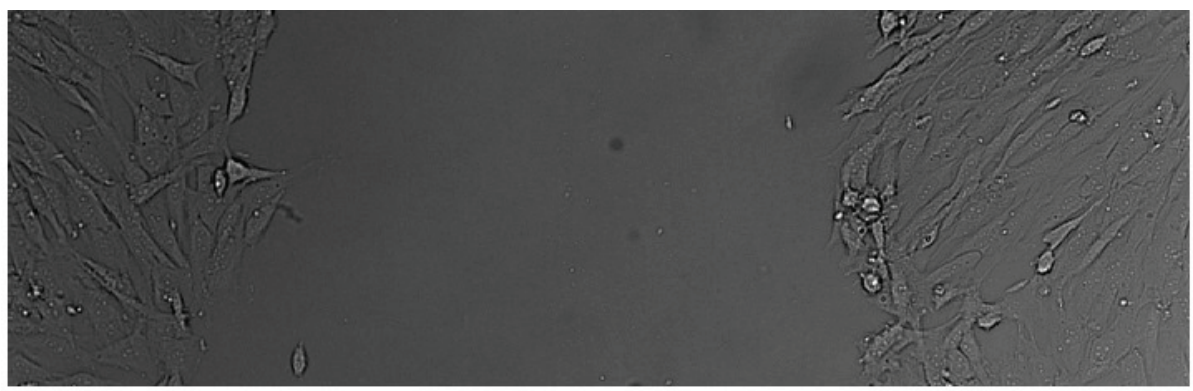

Fig. 8. Illustration of fibroblast scratch assay. Initial scratch (upper photo), scratch on EMF-stimulated dish after 12 hrs (central photo), scratch on control dish after 12 hrs (lower photo). Bar $100 \mu \mathrm{m}$.
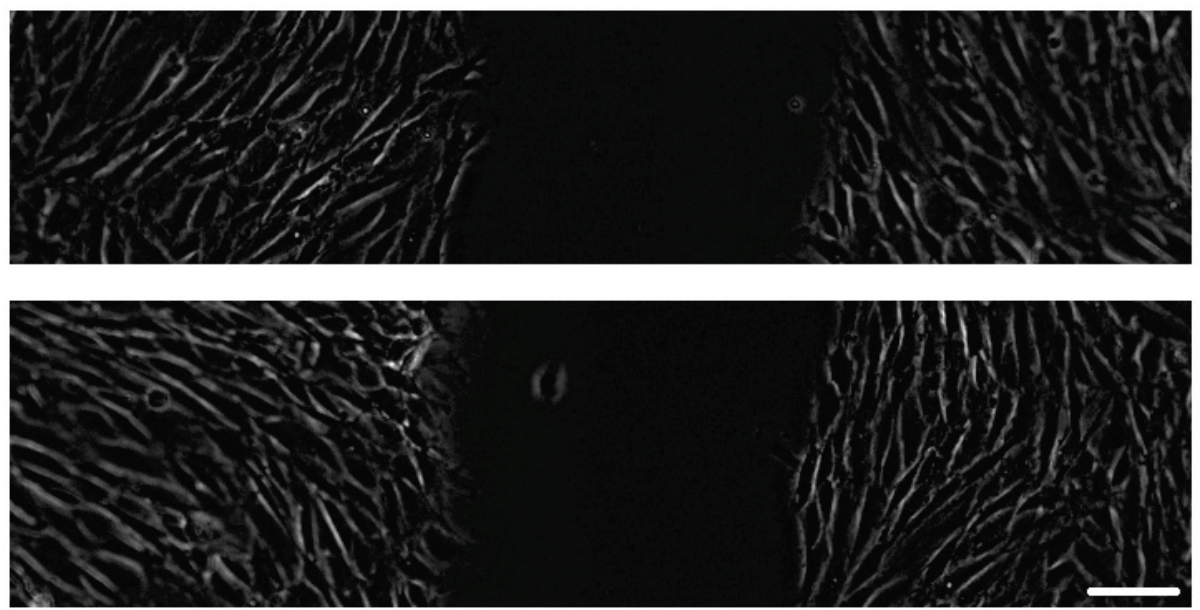

A

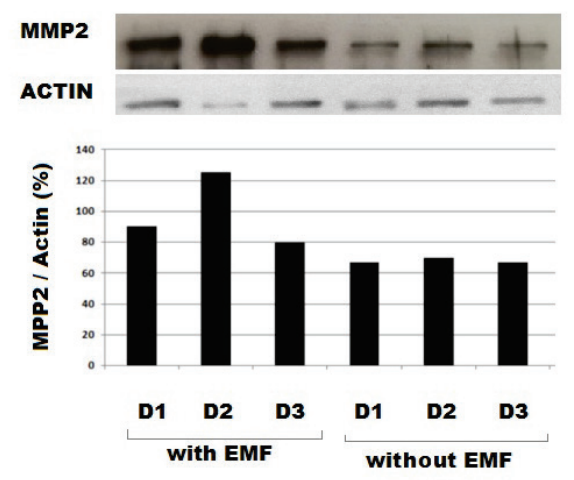

B

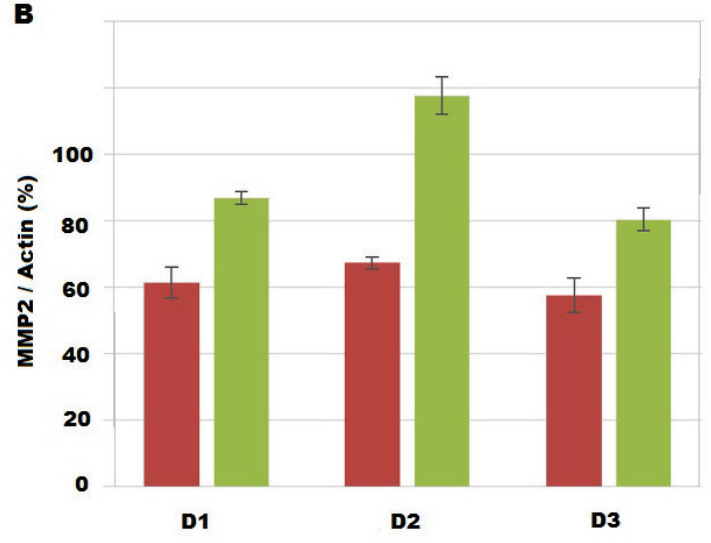

Fig. 9. Western blot detection of MMP-2. (A) Effect of electromagnetic stimulus on MMP-2 expression was evaluated by Western after three days of irradiation (EMF-stimulated sample and control sample from three donors). (B) Statistical summary (each MSC donor is represented by means \pm SD from triplet of WB experiments for control (red) and stimulated cells (green); results for each donor display $p<0.05$ for difference between EMF and control cells).
The tests on the other cell types showed no significant increase in the migration for the DCs and fibroblasts (see Fig. 8). Therefore, the type of EMF used can be called 'MSC specific'.

An increase in MMP-2 production was also found after three days of the EMF stimulation (Fig. 9). MMP-2 activity is important for the migration potential of MSCs in vivo and the correlation between these two factors corresponds with recently published work (De Becker et al. 2007, Cronwright et al. 2005)

\section{Discussion}

MSCs, DCs, and fibroblasts are described in the literature as active migratory cells. MSCs are not very prevalent in adult human bodies, but they are essential after tissue scarring or after ischemic events and promote the stabilization of old tissues and the formation of new functional tissues. In contrast, fibroblasts belong to the most populous cells and are a vital part of connective tissues. Their main role is the mechanical stabilization of many types of tissues in the body, but they also support wound healing and play their role of 'migrating building blocks' during wound closure and the rebuilding of posttraumatic tissues. DCs were the third type of cell examined and these are key messengers in the immune response. DCs intensively migrate from non-lymphatic 
tissues to lymphatic ones and play an important role at the early phase of an immune reaction after invasions of pathogen or cancer cells into the tissue.

Promoting the proliferation of these three types of cells and accelerating their migration potential have been targets of many biomedical and pharmaceutical research groups (Li et al. 2018, Sun et al. 2017, Maharlooei et al. 2011, Zhang et al. 2009). The application of biochemical factors as stimuli for these types of cells is being translated to clinical medicine very slowly, and the process of certifying the chemical's safety is often very complicated.

Parallel to the test of the mentioned chemical stimulus, physical stimuli (including specific EMF pulses) have been tested for a wide set of cell types (Greenebaum 2012, Strauch et al. 2009, Tepper et al. 2004, Wu et al. 2016, Hunckler and De Mel 2017) in proliferation or migration assay; the data from several EMF experiments have shown preliminary positive results. These results have led to the examination of the sensitivity of MSCs, DCs, and fibroblasts to the EMF stimulus. Compared to chemical stimuli, optimized physical stimuli could be applied and localized to a very specific area of the body at a specific optimum time. This represents an advantage as to the certification process and translation to clinical medicine.

\section{Conclusions}

The present work used an EMF generator to produce time-varying magnetic field (characterized by the harmonic carrier frequency of $5000 \mathrm{~Hz}$ modulated by frequencies of 1 to $100 \mathrm{~Hz}$ ), which induced the secondary induced current $\left(\sim 1\right.$ A.m $\left.{ }^{-2}\right)$ in the tissue, which is set to the sample area near the coil (Pitr and Prucha 2001, Prucha et al. 2004). The effects of these currents on MSCs, DCs, and fibroblasts were quantified after a short irradiation procedure (three days; 90-300 $\mathrm{min} /$ day). The first test looked at the cell viability after the EMF exposure and the calcein assay and microscope overview did not show any increase in cell death in the samples after the EMF application. The ROS production after the EMF application was measured by CM-H2DCFDA to quantify early changes in cell physiology. This method is very sensitive to cell stress even several $h$ before apoptosis or cell malformation begins. The CM-H2DCFDA assay determines the rate of production of hydrogen peroxide $\left(\mathrm{H}_{2} \mathrm{O}_{2}\right)$, hydroxyl radical ( $\left.\mathrm{HO}\right)$, and superoxide $\left(\mathrm{O}_{2}{ }^{-}\right)$in cells and a small increase in ROS in the first or second day was visible in all cell cultures. The value on the third day showed a decrease to the initial value (Fig. 4), but the time profile indicates some adaptation of the cells to the EMF stimulus. Finally, the MTT assay showed no statistical change in the metabolic activity or proliferation of MSCs, DCs, or fibroblasts during the three days of EMF irradiation.

The main results of the present work were derived from cell migration tests. The tests based on migration assays the MSC sensitivity to the used type of the time-varying magnetic field EMF; the sensitivity of DCs and fibroblasts was quantified as negligible. The migratory potential of MSCs increased by a factor of 1.4 compared to the control cells - an increase that is comparable with the biochemical pre-stimulation of MSCs by pharmaco-active compounds IGF (Li et al. 2007) or TNF-alpha (Ponte et al. 2007). More advanced future testing of the effect of EMF should look at specific environmental conditions, e.g. a hypoxic cell environment or the addition of tissue elements from apoptotic cells to mimic chronic wounds or infarcted tissue.

The fact that none of the tested cells stimulated by the EMF displayed a negative trend in the cell proliferation, cell viability, or cell morphology, is a very important finding for the future evaluation of the clinical safety for using our EMF generator from the viewpoint of the different 'background' tissue in the body (excluding of negative effect on the background tissue).

We can summarize that the current study found an important sensitivity of MSCs to specific time-varying EMF (effect on migratory function). The results were obtained under standard in vitro conditions (DMEM medium, $5 \% \mathrm{CO}_{2}$ in atmosphere). Therefore, the same EMF stimulus should also be tested in another specific environmental conditions mimicking in vivo pathology to examine its effects on the production of paracrine bioactive molecules (cytokines, grow-factors) by MSCs and other parameters of regenerative process (this release of bioactive molecules could be very important for the autocrine stimulation and paracrine stimulation of cells in the microenvironment of MSCs. These bioactive molecules have been described in many studies as natural autologous activators of the fibroblast proliferation, endothelial cell proliferation, immunomodulation, and other regenerative processes (Li et al. 2018, Sun et al. 2017, Maharlooei et al. 2011). MSCs could significantly increase the neoangiogenesis and reduce wound size via the intense release of VEGF at a specific time point of the 
tissue regeneration). The current work offers the first indication of the effective pre-stimulation of MSCs by specific time-varying EMF, suggesting that the acceleration of the MSCs migration to the pathological site of tissue could upgrade clinical methods in the near future.

\section{Conflict of Interest}

There is no conflict of interest.

\section{Acknowledgements}

This work was supported by the Health Research Agency of the Ministry of Health of the Czech Republic within the implementation of the project "Affection of the locomotive apparatus degenerative diseases symptoms by means of high-induction magnetic stimulation" (No. 16-28784A). The present study was also funded by the Ministry of Industry and Trade of the Czech Republic within the framework of the project No. FV20422 "Development of nanofibrous scaffolds ensuring application of cellular products, including physical stimulation effect, with the intended purpose of the treatment of chronic wounds". The authors would like to thank prof. dr. Miloslav Rakovič, DrSc., for his help with the translation of the manuscript.

\section{References}

ALtANER C, Altanerova U: Mesenchymal Stem Cell Exosome-Mediated Prodrug Gene Therapy for Cancer. In: Suicide Gene Therapy, Humana Press, New York, 2019, pp 75-78.

ALTANEROVA U, JAKUBECHOVA J, REPISKA V, ALTANER C: Exosomes of human mesenchymal stem/stromal/medicinal signaling cells. Neoplasma 64: 809-815, 2017.

CAPEK F, PRUCHA J, SOCHA V, HART V, BURDA H: Directional orientation of pheasant chicks at the drinking dish and its potential for research on avian magnetoreception: Folia Zoologica 66: 175-183. 2017.

CMIEL V, SKOPALIK J, POLAKOVA K, SOLAR J, HAVRDOVA M, MILDE D, PROVAZNIK I: Rhodamine bound maghemite as a long-term dual imaging nanoprobe of adipose tissue-derived mesenchymal stromal cells. Europ Biophys J 46: 433-444, 2017.

CRONWRIGHT G, LE BLANC K, GÖTHERSTRÖM C, DARCY P, EHNMAN M, BRODIN B: Cancer/testis antigen expression in human mesenchymal stem cells: down-regulation of SSX impairs cell migration and matrix metalloproteinase 2 expression. Cancer Res 65: 2207-2215, 2005.

DE BECKER A, VAN HUMMELEN P, BAKKUS M, VAN DE BROEK I, WEVER J, DE WAELE M, VAN RIET I. Migration of culture-expanded human mesenchymal stem cells through bone marrow endothelium is regulated by matrix metalloproteinase-2 and tissue inhibitor of metalloproteinase-3. Haematologica 92: 440-449, 2007.

GREENEBAUM B: Induced electric field and current density patterns in bone fractures. Bioelectromagnetics 33: 585-593, 2012.

GUIDELINE, ICNIRP: Guidelines for limiting exposure to time-varying electric, magnetic, and electromagnetic fields (up to $300 \mathrm{GHz}$ ). Health Phys 74: 494-522, 1998.

HUNCKLER J, DE MEL A: A current affair: electrotherapy in wound healing. J Multidisciplin Healthcare 10: 179, 2017.

LI Y, YU X, LIN S, LI X, ZHANG S, SONG Y: Insulin-like growth factor 1 enhances the migratory capacity of mesenchymal stem cells. Biochem Biophys Res Commun 356: 780-784, 2007.

LI XJ, HUANG FZ, WAN Y, LI Y, ZHANG WK, XI Y, TIAN H, TANG B: Lipopolysaccharide stimulated the migration of nih3t3 cells through a positive feedback between $\beta$-catenin and COX-2. Front Pharmacol 9: 1487, 2018.

LI Y, YU X, LIN S, LI X, ZHANG S a SONG Y: Insulin-like growth factor 1 enhances the migratory capacity of mesenchymal stem cells. Biochem Biophysic Res Comm 356: 780-784, 2007.

MAHARLOOEI MK, BAGHERI M, SOLHJOU Z, JAHROMI BM, AKRAMI M, ROHANI L, MONABATI A, NOORAFSHAN A, OMRANI GR: Diabetes Res Clin Pract 93: 228-234. 2011.

MICHALEK J, VRABLIKOVA A, DARINSKAS A, LUKAC L, PRUCHA J, SKOPALIK J, TRAVNIK J, CIBULKA M, DUDASOVA Z: Stromal vascular fraction cell therapy for osteoarthritis in elderly: Multicenter casecontrol study. J Clin Orthop Trauma 10: 76-80, 2019. 
PITR K, PRUCHA J: Regression of pain of the locomotor apparatus and other effects associated with application of distance electrotheraphy. Rehabilitace a Fyzikalni Lekarstvi 8: 70-85, 2001.

PONTE AL, MARAIS E, GALLAY N, LANGONNÉ A, DELORME A, HÉRAULT O, CHARBORD P, DOMENECH $\mathrm{J}$ : The in vitro migration capacity of human bone marrow mesenchymal stem cells: comparison of chemokine and growth factor chemotactic activities. Stem Cells 25: 1737-1745, 2007.

PRUCHA J, HAVEL V, PITR K: The physical conditions of the distant electrotherapy application in patients with metallic endoprosthesis (in Czech). Rehabilitace a Fyzikalni Lekarstvi 11: 184-188, 2004.

PRUCHA J, KRUSEK J, DITTERT I, SINICA V, KADKOVA A, VLACHOVA V: Acute exposure to high-induction electromagnetic field affects activity of model peripheral sensory neurons. J Cell Mol Med 22: 1355-1362, 2018.

SAKAR MS, EYCKMANS J, PIETERS R, EBERLI D, NELSON BJ, CHEN S: Cellular forces and matrix assembly coordinate fibrous tissue repair. Nat Com 7: 11036, 2016.

SHUPAK NM, PRATO FS, THOMAS AW: Therapeutic uses of pulsed magnetic-field exposure: a review. URSI Radio Sci Bulletin 76: 9-32, 2003.

SICILIANO C, BORDIN A, IBRAHIM M, CHIMENTI I, CASSIANO F, GATTO I, PETROZZA V: The adipose tissue of origin influences the biological potential of human adipose stromal cells isolated from mediastinal and subcutaneous fat depots. Stem Cell Res 17: 342-351, 2016.

SKOPALIK J, PASEK M, RYCHTARIK M, KORISTEK Z, GABRIELOVA E, SCHEER P, KLABUSAY M: Formation of cell-to-cell connection between bone marrow cells and isolated rat cardiomyocytes in a cocultivation model. $J$ Cell Sci Therapy 5: 1, 2014.

STRAUCH B, HERMAN C, DABB R, IGNARRO LJ, PILLA AA: Evidence-based use of pulsed electromagnetic field therapy in clinical plastic surgery. Aesthet Surg J 29: 135-143, 2009.

STRIOGA M, SCHIJNS V, POWELL Jr D J, PASUKONIENE V, DOBROVOLSKIENE N, MICHALEK J: Dendritic cells and their role in tumor immunosurveillance. Innate Immunol 19: 98-111, 2013.

SUN Z, LIU C, PAN T, YAO H, LI S: Selenium accelerates chicken dendritic cells differentiation and affects selenoproteins expression. Develop Compar Immunol 77: 30-37, 2017.

SYLVESTER PW: Optimization of the tetrazolium dye (MTT) colorimetric assay for cellular growth and viability. Methods Mol Biol 716: 157-168, 2011.

TEPPER OM, CALLAGHAN MJ, CHANG EI, GALIANO RD, BHATT KA, BAHARESTANI S, GAN J, SIMON B, HOPPER RA, LEVINE JP, GURTNER GC: Electromagnetic fields increase in vitro and in vivo angiogenesis through endothelial release of FGF-2. FASEB J 18: 1231-1233, 2004.

VOPENKOVA K, MOLLOVA K, BURESOVA I, MICHALEK J: Complex evaluation of human monocyte-derived dendritic cells for cancer immunotherapy. Journal of cellular and molecular medicine 16: 2827-2837, 2012.

WU Y, HUA Y, XIONG Z, WU L, YAO C, ZHANG R, WANG Z: Picosecond pulsed electric field inhibits the proliferation and migration, induces $\mathrm{G} 2 / \mathrm{M}$ phase arrest and promotes apoptosis in human umbilical venous endothelial cells. Ch J Cell Molecul Immunol 32: 319-322, 2016.

ZHANG B, LIU R, SHI D, CHEN Y, LIANG W, LIAO L, ZENKE M, ZHAAO ECH: Mesenchymal stem cells induce mature dendritic cells into a novel Jagged-2-dependent regulatory dendritic cell population. Blood 113: 46-57, 2009. 